\title{
Tarım Makinaları İmalatı Yapan Bir Firmada Gürültü Analizi
}

\author{
Noise Analysis at a Company Manufacturing Agricultural Machinery
}

Ergun ATEŞ, Merve Gül ALAGÖZ

\begin{abstract}
ÖZET
Tarım makinaları imalatı yapan bir fabrikada çalışanlar üzerine gürültünün işitme kaybı açısından etkilerinin incelenmesi çalıșılmıștır. İşyerinde tezgâhların ve aletlerin motor güçleri ve üretilen ürünlerin operasyonlarına bağlı olarak gürültü değerleri ölçülmüsstür. Ölçülen değerler de en yüksek gürültü değeri $86.1 \mathrm{~dB}(\mathrm{~A})$ ve devamında diğer dört birimde 82.1-75.7 dB(A) olarak ölçülmüştür. Yönetmeliklere ve literatür çalışmalarına göre iş yeri risk olarak kabul edilen $85 \mathrm{~dB}(\mathrm{~A})$ gürültü seviyesi değerleri için yönetmeliklerde tanımlanan koruyucu önlemlerin alınması gerekir. Özellikle yüksek değer ve aşağı gürültü seviyelerine doğru ölçüm alınan birime göre, çalışanların mevcut gürültü seviyesinde işitme sağlığı üzerine etkilerinin ölçülmesi ve zamana bağlı sürdürülebilir kontrollerinin yapılması uygun görülmektedir.
\end{abstract}

Anahtar Kelimeler: Gürültü, İmalat, İş Güvenliği, İş Sağlığı

\section{ABSTRACT}

This study reviewed the hearing loss-related effects of noise on workers employed at a factory manufacturing agricultural machinery. Noise levels were measured by taking into account the engine powers of the workbenches and tools, as well as the operations of the manufactured products. Of the measured levels, the highest noise level was of $86.1 \mathrm{~dB}(\mathrm{~A})$, followed by four other units with a noise level of 82.1-75.7 $\mathrm{dB}(\mathrm{A})$. The concerned people should take the protective measures stipulated in regulations for the noise level of $85 \mathrm{~dB}(\mathrm{~A})$, which is considered a workplace risk according to the relevant regulations and literature works. Based particularly on the unit where a measurement was carried out towards high value and low noise levels, it was concluded that the hearing health-related effects on workers at the existing noise level should be measured and timedependent sustainable checks should be performed.

Keywords: Noise, Manufacturing, Occupational Safety, Occupational Health

Doç.Dr.Ergun ATEŞ - Balıkesir Üniversitesi Mühendislik Fakültesi Makina Mühendisliği Bölümü, Balıkesir, Türkiye

Assoc. Prof. Ergun ATES - Balikesir University, Faculty of Engineering, Department of Mechanical Engineering, Balikesir, Turkey ergunates@balikesir.edu.tr

Merve Gül ALAGÖz - Balıkesir Üniversitesi Mühendislik Fakültesi Makina Mühendisliği Bölümü, Balıkesir, Türkiye Merve Gul ALAGOZ - Balikesir University, Faculty of Engineering, Department of Mechanical Engineering, Balikesir, Turkey mervegulalagoz@baun.edu.tr 


\section{GİRIŞ}

Gürültü, üretim faaliyetlerinin olduğu her birimde çalışanlar için önemli bir problemdir. Çalışanların rutin çalışma süreleri dışında, uzayan iş süreleri de söz konusu olduğunda gürültü daha da önemli bir sorun haline gelmektedir. Gürültü problemi iş verimini olumsuz etkilemektedir. Çalışma ve Sosyal Güvenlik Bakanlığının akredite ettiği kuruluşlar tarafından gürültü oluşan iş yerlerinde ölçümler yapılıp iş yeri gürültü analizinin yapılması gerekir. İşverene düşen yükümlülük, uygulamada aksaklık olmaması için gerekli tedbirleri almak ve bunun sürdürülebilir olmasını sağlamaktır.

"Çalışanların gürültü İle İlgili Risklerden Korunmalarına Dair Yönetmeliğin 8.Maddesine Göre; Maruziyetin Önlenmesi Ve Azaltılması Sorumluluğu İşverenindir", demektedir. Aynı yönetmeliğin 5.maddesine göre LEX,8saat olmak üzere maruziyet değerleri ' en düşük 80 $\mathrm{dB}(\mathrm{A})$, en yüksek $85 \mathrm{~dB}(\mathrm{~A})$, sınır değeri ise $87 \mathrm{~dB}(\mathrm{~A})$ olarak verilmiştir [1].

Besicilikte, kapalı bir alanda hasat sonrası kullanılan çekiçli yem kırma makinası üzerinde gürültü ölçümü yapılmıştır. Çalışmada gürültü düzeyi uyarı sınırı $85 \mathrm{~dB}(\mathrm{~A})$, gürültü düzeyi tehlike sınırı ise $95 \mathrm{~dB}(\mathrm{~A})$ olarak alınmıştır. Çekiçli yem kırma makinasının gürültü düzeyi $98 \mathrm{~dB}(\mathrm{~A})$ ölçülmüş ve bu değerin yüksek olmasından dolayı önlem alınması, gürültü çıkaran makinanın daha az gürültü çıkaran bir makinayla değiştirilmesi gerektiği belirlenmiştir [2] . Bir termik santralde 15 yıllık süreçte oluşan kazalar incelendiğinde mutlaka risk faktörlerinin belirlenmesi ve koruyucu önlemlerin alınması gereği vurgulanmıştır [3]. Bir tekstil işletmesinde çözgü sarma, ağızlık açma, atkı atma, tefe vurma ve kumaş sarma makinelerinden gürültü ölçümleri yapılmış ve bu ölçümler makinelerden 1 m uzak- lıkta ve yerden 1 metre yükseklikte gerçekleştirilmiştir. Gürültü ölçümleri sonucunda gürültü seviyesinin $85 \mathrm{~dB}$ in üzerinde olduğu tespit edilmiş ve ortamdaki ses seviyesini azaltmak için çözümler üretilmeye başlanmıştır. [4]. Bir konfeksiyon firmasında risk etmenleri değerlendirildiğinde gürültü ölçümlerinin sınır değerlerine bazı kısımlarda yakınlaştığı belirlenmiş ve çalışanların gürültü kontrol yönetmeliğine göre işitme ve dikkat üzerine eğitilmeleri gereği açıklanmıştır [5]. Madencilikte gürültü sorunu ve gürültüye bağlı işitme kayıpları incelenmiş, çalışan işçilerde gürültü sonucu oluşan işitme kayıpları ve tipleri belirlenmiştir [6]. Bir çalışmada takım tezgâhlarının sebep olduğu gürültü ve bu nedenle verim kaybı çalışılmış ve sonuçlar tezgâhlardan yayılan gürültüye dikkat edilmesi gereğini göstermiştir [7]. Doğal taş işleme de kayaları kesmek için genelde elmas soketli dairesel testereler kullanılmaktadır. Böyle bir kesim sırasında malzemeye bağlı olarak belirlenmiş çevresel hızda oluşan gürültü seviyeleri ölçülmüştür. Testere boşta ve yükte çalıştırıldığında ortalama $85-95 \mathrm{~dB}$ seviyelerine ulaşılmıştır [8]. Küçük ölçekli mobilya işletmelerinde gürültü çalışılmıştır. Seçilen 450 işletmede 5460 gürültü ölçümü yapılmıştır. İşletmelerde kullanılan makine çeşitliliğine rağmen ortalama değer hesaplanmıştır. Makineler yüklü çalışırken ortalama en yüksek ölçüm planya 'da $95.17 \pm 4,5$ $\mathrm{dB}(\mathrm{A})$, boş durumda çalışıyorken ise ortalama en yüksek değer CNC tezgâhında 88.09ะ0.036 dB(A), olarak ölçülmüştür. Gürültü, çalışanların sağlığını tehlikeye atacak boyutlara ulaştığından ve bu etkiye maruz kalınan çalışma süresi arttığında, çalışanlarda fizyolojik ve psikolojik sağlık sorunlarının oluşabileceği belirlenmiştir [9]. Isı ve gürültü maruziyetinin çalışıldığı küçük ve orta ölçekli döküm, dövme endüstrisinde 350 erkek işçi denek olarak alınmış ve ölçümler sonucu 90 dB(A)'dan daha yüksek gürültü değerleri belirlenmiştir. Yüksek seviyeli 1sı ve gürültü etkisinin 60-72 saat/hafta çalışma sürelerinin yüksek olduğu ve ko- 
ruyucu önlemlerin alınma zorunluluğu açıklanmıştır [10]. Küçük ve orta ölçekli metal malzeme imalatı işletmelerinde gürültü araştırılmıştır. İş alanı 3, fabrika 3, imalat işlemi 40 parametreleri için 250 noktada gürültü ölçülmüştür. Buradan imalat işlemlerinde ses kaynakları ve frekanslar veri olarak toplanmıştır [11]. Gürültünün işçiler üzerindeki olumsuz etkilerini tespit etmek amacıyla mobilya üretimi yapan 3 adet küçük ve orta ölçekli işletmede 4 değişik makine ile çalışan işçiler üzerinde ölçüm yapılmıştır.

Ölçümler sonucu tehlike sınırı 87 dB(A)'dan daha yüksek gürültü değerlerinin olduğu belirlenmiştir. İşçilerin maruziyet miktarlarının azaltılması ve gerekli önlemlerin alınması gerektiği açıklanmıştır [12]. Ekonomik İşbirliği ve Kalkınma Örgütü (OECD) tarafından 1996 yılında yayınlanan bir raporda, gürültünün herkesi etkileyen bir etki olduğu açıklanmışıı. Rahatsızlık verme başlangıcı olan gürültü değeri 55-60 dB(A), rahatsılığın belirgin şekilde artması $60-65 \mathrm{~dB}(\mathrm{~A})$ ve gürültü değerinin $65 \mathrm{~dB}(\mathrm{~A})$ üzeri olması ise davranış biçiminde engellemeler oluşturacağı şeklinde detaylandırılmışıtır [13].

Literatürde imalat işlemleri için belirtilen gürültü değerleri $85 \mathrm{~dB}$ üzeridir. Bu durum çalışanların sağlığı adına önlem almayı gerektirir [14,15]. Bu çalışmada Balıkesir il merkezi sanayi bölgesinde yer alan bir tarım makinaları imalatı yapan fabrikada, oluşan gürültünün ölçülmesi ve değerlendirilmesiyle, çalışan sağlığı korunması, iş veriminin arttırılması, varsa eksikliklerin tamamlanması hedeflenmiştir. İlgili firmada daha önce benzeri bir çalışma yapılmamıştır.

\section{MALZEME VE METOT}

Firmada ortam gürültüsü ölçümleri $\mathrm{A}$ bandında $\mathrm{dB}(\mathrm{A})$ olarak alınmıştır [16]. Her bir ölçüm süresi 3 dakikadır. Ölçümlerde SC310 CESVA “Sound Level Meter" kullanıl- mıştır. Ölçümlerin değerlendirilmesinde cihazın yazılımı aracılı̆̆ı ile veriler değerlendirilerek, ölçüm ortalamaları alınmıştır. Fabrikada 9 üretim ve 3 idari odaklı birim bulunmaktadır. Fabrika bölümlerinden olan atölyelerde tezgahların yerleşimleri ve her bir atölyenin tanımlandığı sembol harfler A 'dan L'ye kadar fabrika planları üzerine işlenmiştir (Şekil 1 ve Şekil 2).

Ölçüm yapılan noktalar her bir birimin merkezi olarak seçilmiştir. Fabrikada çalışma saatleri dışında ve çevreden gelen gürültü etkenlerinin devre dışı bırakılıp daha sağlıklı bir değerlendirme için öncelikle sessiz olarak ölçümler yapılmıştır. Devamında fabrikada işçilerin ve tezgâhların çalıştı̆̆ aktif çalışma saatlerinde de sesli olarak ölçümler yapılmıştır. Sessiz ve sesli ölçüm değerleri Tablo 1'de verilmiştir.

Fabrikada farklı birimlerde yer alan çalışan tüm makinalar iş̧̧ilerin maruz kaldığı toplam gürültü kaynağıdır. Fakat bu makinaların hepsi aynı anda çalışmamaktadır. İmalat sürecine dahil olan aşamalara göre, atölyelere yarı mamül girişinden montaja gelene değin, şekillendirilen parçalar farklı makinalarda farklı kuvvetler etkisinde kaldıklarından, gürültüye katkıları da farklı seviyelerde olmaktadır. Doğru gözlem yaparak mümkün olduğunca imalat sürecine uygun tüm etkileri yansıtabilecek gürültü değerleri alabilmek önemlidir. Bu ancak ölçümlerin, tümü temsil edebilecek şekilde, uzun süreli yapılmasını gerektirir. $\mathrm{Bu}$ çalışmada üretimler çeşitli olsa da, işçilerin maruz kaldığ farklı iş tipleriyle çalışırken yapılan ölçümler önemsenmiştir.

Fabrikada bulunan makinalar tasarımları gereği çalıştıklarında kendisini tahrik eden ana kaynağın gücüne ve elemanların konumlarına bağlı olarak gürültü yüksek veya alçak olabilir. Bu nedenle tüm makinaların tahrik edildiği güç değerleri Tablo 2'de verilmiştir. 
Şekil 1: Fabrikada atölyelerin yerleşimi ve harflerle tanımlanan ölçüm noktaları

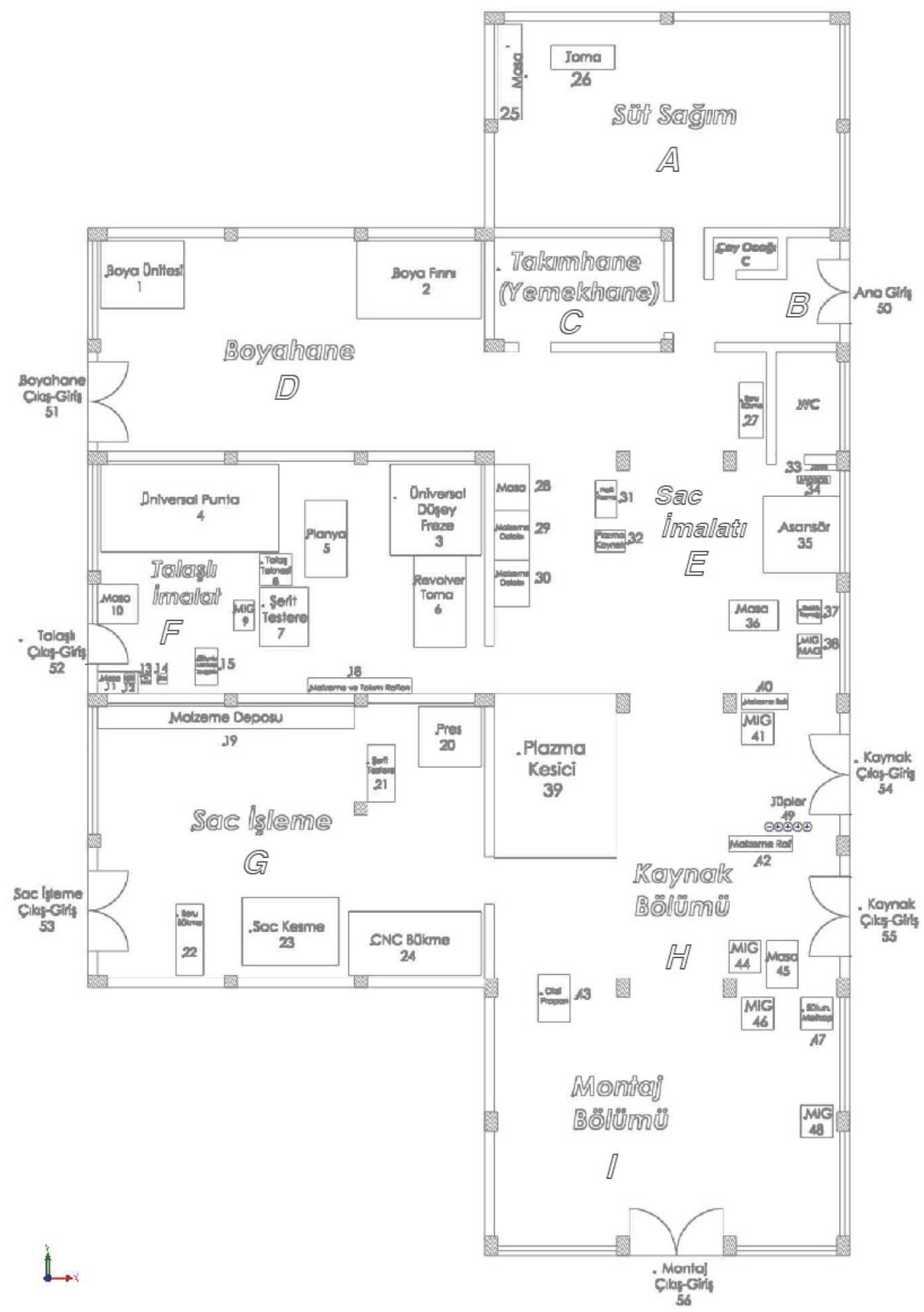


Şekil 2: Fabrikada idari kullanım alanlarının harflerle tanımlanan ölçüm noktaları

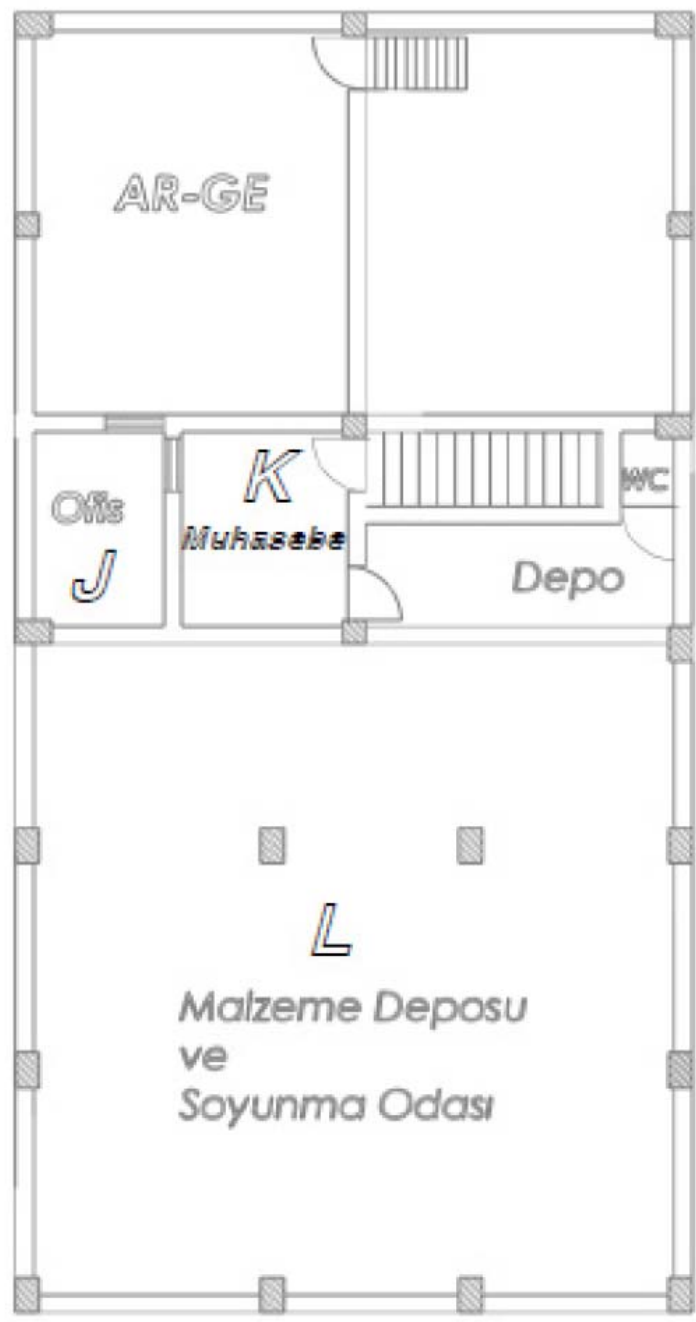

Tablo 1: Fabrikadan alınan sessiz ve sesli ölçümler

\begin{tabular}{|c|c|c|c|}
\hline Yer & Sembol & Sessiz & Sesli \\
\hline \multirow{9}{*}{$\frac{\frac{\grave{d}}{0}}{\sum_{\overline{0}}^{\frac{0}{\alpha}}}$} & A & 48.7 & 62.8 \\
\hline & B & 54.4 & 69.2 \\
\hline & C & 38.4 & 61.8 \\
\hline & D & 45.9 & 69.2 \\
\hline & $\mathrm{E}$ & 46.1 & 75.7 \\
\hline & $\mathrm{F}$ & 46.6 & 79.3 \\
\hline & G & 42.2 & 76.1 \\
\hline & $\mathrm{H}$ & 43.6 & 86.1 \\
\hline & 1 & 43.4 & 82.1 \\
\hline \multirow{5}{*}{$\begin{array}{l}\overline{5} \\
\text { 증 }\end{array}$} & $\mathrm{J}_{\mathrm{KA}}$ & 39.2 & 48.2 \\
\hline & $\mathrm{J}_{\mathrm{KK}}$ & 33.4 & 43.3 \\
\hline & $\mathrm{K}_{\mathrm{KA}}$ & 49.2 & 55.1 \\
\hline & $\mathrm{K}_{\mathrm{KK}}$ & 48.2 & 48.4 \\
\hline & L & 44.9 & 61.4 \\
\hline
\end{tabular}

Elektrikle çalışan tüm makinaların tahrik edildiği güç kaynağı elektrik motorudur. Hareketin alındığı noktadan iş gören makinanın nihai yerine kadar, amaca uygun olarak tasarlanmış ve çok farklı büyüklüklere sahip yapılardır. Yapının kendisi ve işlediği eleman dışında ana güç kaynağı tarafından da bir gürültü ortaya çıkmaktadır ve Tablo 2 verileri bu açıdan önemlidir. Aslında ölçülen gürültü değerleri ilgili elektrik motorlarının da tahriki anında elde edilen değerlerdir. Elektrik motorunun gücünün büyük

Tablo 2: Fabrikada var olan elektrikli makinalar ve güçleri

\begin{tabular}{|c|c|c|c|c|c|}
\hline Yer Sembolü & Makina & Güç (kW) & Yer Sembolü & Makina / Özellik & Güç (kW) \\
\hline$A$ & Torna (1m) & 3.0 & G & Testere & 2.2 \\
\hline $\mathrm{F}$ & Torna (3m) & 11.0 & G & Boru Bükme & 1.5 \\
\hline $\mathrm{F}$ & Düşey Freze & 5.5 & $E$ & Gazalt Kaynak (350 A) 2 Adet & - \\
\hline $\mathrm{F}$ & Planya & 3.0 & $\mathrm{H}$ & Gazalt Kaynak (350 A) 2 Adet & - \\
\hline $\mathrm{F}$ & Sütunlu Matkap & 1.5 & $\mathrm{H}$ & Elektrik Ark Kaynak (350 A) 1 Adet & - \\
\hline $\mathrm{F}$ & Testere & 2.2 & 1 & Oksi-Asetilen Kaynak 1 Adet & - \\
\hline $\mathrm{F}$ & H. Pres (60ton) & 2.2 & I & Gazalt Kaynak (350 A) 2 Adet & - \\
\hline G & Abgant Pres & 5.5 & $\mathrm{E}, \mathrm{H}, \mathrm{I}$ & Küçük Spiral $(\varnothing 110 \mathrm{~mm}) 3$ Adet & 0.75 \\
\hline G & Eksantrik Pres & 7.5 & $\mathrm{E}, \mathrm{H} . \mathrm{I}$ & Büyük Spiral ( $\varnothing 180 \mathrm{~mm}) 3$ Adet & 1.5 \\
\hline G & Giyotin Makas & 7.5 & Teras (Dış) & Vidalı Kompresör Maksimum 8 bar & 15 \\
\hline
\end{tabular}


olması doğal olarak tahrik ettiği makinanın da büyük kütlelerden ibaret olduğunu bu nedenle küçük bir yapıyla kıyaslandığında daha büyük gürültü değerlerini verebileceği söylenebilir. Tablo 2'de 15 kW'lık vidalı kompresör hacim olarak da ilave elemanları da düşünüldüğünde yaklaşık 2 m3 bir hacim kaplamaktadır ve ana makinanın çalışması kapalı mekânda $75 \mathrm{~dB}(\mathrm{~A})$ ses üretmektedir. Fakat kompresör sistemi iç mekânda olmayıp ikinci katta terasta yerleştirilmiş olduğundan fabrika içerisine yansıyan herhangi bir gürültü katkısı yoktur.

Tablo 2'deki fabrika içerisinde, F talaşlı imalat atölyesinde bulunan torna tezgâhı iç birimdeki en büyük güce sahiptir. Tahrik ettiği torna tezgahında $79.3 \mathrm{~dB}(\mathrm{~A})$ elde edilmiş olması ve işin yapısına göre yükselip alçalabilmektedir. Aynı atölyede bulunan diğer beş tezgâh bu gücün yarısı ve diğerleri de daha düşük güçtedirler. Bazen düşük güçte olsa işin yapısı gereği büyük gürültü değerleri alınabilmektedir.

Sac işleme bölümünde preslerin güçlerine göre iş görme anında üretilen gürültü belirli bir periyodun içinde bir darbe şeklindedir. Dolayısıyla uzun süreli çalışma saatlerinde büyük güce sahip olsa da bunun gürültüye etkisi sınırlı olmaktadır.

Spiraller büyüğü küçügünden daha fazla olmak üzere, kesici veya taşlama taşının baskı kuvvetine bağlı olarak belirli bir süre oldukça rahatsız edici gürültü değerleri oluşturmaktadırlar. Yapılan kaynak işlemlerindeki ve plazma ürünü saclardaki çapakların tümünün temizlenmesinde sık başvurulan dolayısıyla gürültü kaynağı olan makinalardır.

Kaynak makinalarında ise gürültü büyükten küçüğe olmak üzere sırasıyla elektrik ark, gaz altı, oksi-asetilen şeklindedir ve tek çalıştığında bu değerlerin en büyüğü 75 dB(A)'ya kadar çıkabilmektedir.

\section{III. ÖLÇÜMLERİN DEĞERLENDİRİLMESİ}

Fabrikada atölyeden alınan sessiz ve sesli ölçümlerin, "Atölyelerin Sembolleri-dB(A)" eksenlerinde gösterimi Şekil 3'de verilmiştir. Atölyeleri gösteren dokuz bölümde sessiz halde alınan ölçümlerden, $38.4 \mathrm{~dB}(\mathrm{~A})$ olarak en düşük değer yemekhane olarak da kullanılan takımhane de ölçülmüştür. Sessiz ölçümlerde en büyük değer ise sac imalatı ve süt sağım arasında kalan ana girişte $54.4 \mathrm{~dB}(\mathrm{~A})$ olarak ölçülmüştür. Girişte en büyük değerin alınması, hafta sonu ve ölçüm yapılan fabrikanın çalışmıyor olmasına rağmen, çevredeki diğer fabrikaların çalışıyor olmaları ve çevreden gelen gürültü sebebi ile olduğu söylenebilir.

Fabrika çalışıyor iken atölyelerden yapılan sesli ölçümlerden en küçük değer $61.8 \mathrm{~dB}(\mathrm{~A})$ ile yine takımhane de ölçülmüştür. Sesli ölçülen en büyük değer ise $86.1 \mathrm{~dB}(\mathrm{~A})$ değeri ile montaj bölümünden alınmıştır. Bu bölüm aralarında herhangi bir perde olmayan, aynı hangarın üç farklı bölümü şeklindedir ve bir gerisinde kaynak bölümü onunda bir gerisinde sac imalatı yapılan bölümler yer almaktadır. Şekil 1'den de görülebileceği gibi kaynak bölümünün yan tarafından $G$ ile verilen sac işleme bölümü de görülmektedir. Sac işleme ve sac imalatı bölümlerinde çalışan büyük presler, çalışan spiral, bazen devreye giren plazma ve genelde çok yoğun kullanılan kaynak makinaları ilaveleri nedeniyle, oldukça yoğun gürültünün olduğu bir bölge haline gelmektedir.

Mevcut binada F ve G ile tanımlanan talaşlı imalat ve saç işleme bölümleri ara duvarlarının kalınlıkları normal yapıya göre daha büyük ölçüde (sırasıyla $44 \mathrm{~cm}$ ve $55 \mathrm{~cm}$ olarak) yapılmış olup, sac imalatından talaşlı imalat bölümüne ve saç işleme bölümüne giriş dar bir ara geçişi halinde kalmıştır. Bu yapı oluşumu nedeniyle talaşlı imalatta oluşan gürültünün sac imalatı bölgesine geçişini ve tersi 
Şekil 3: Fabrikada atölyelerden alınan sessiz ve sesli gürültü değerleri

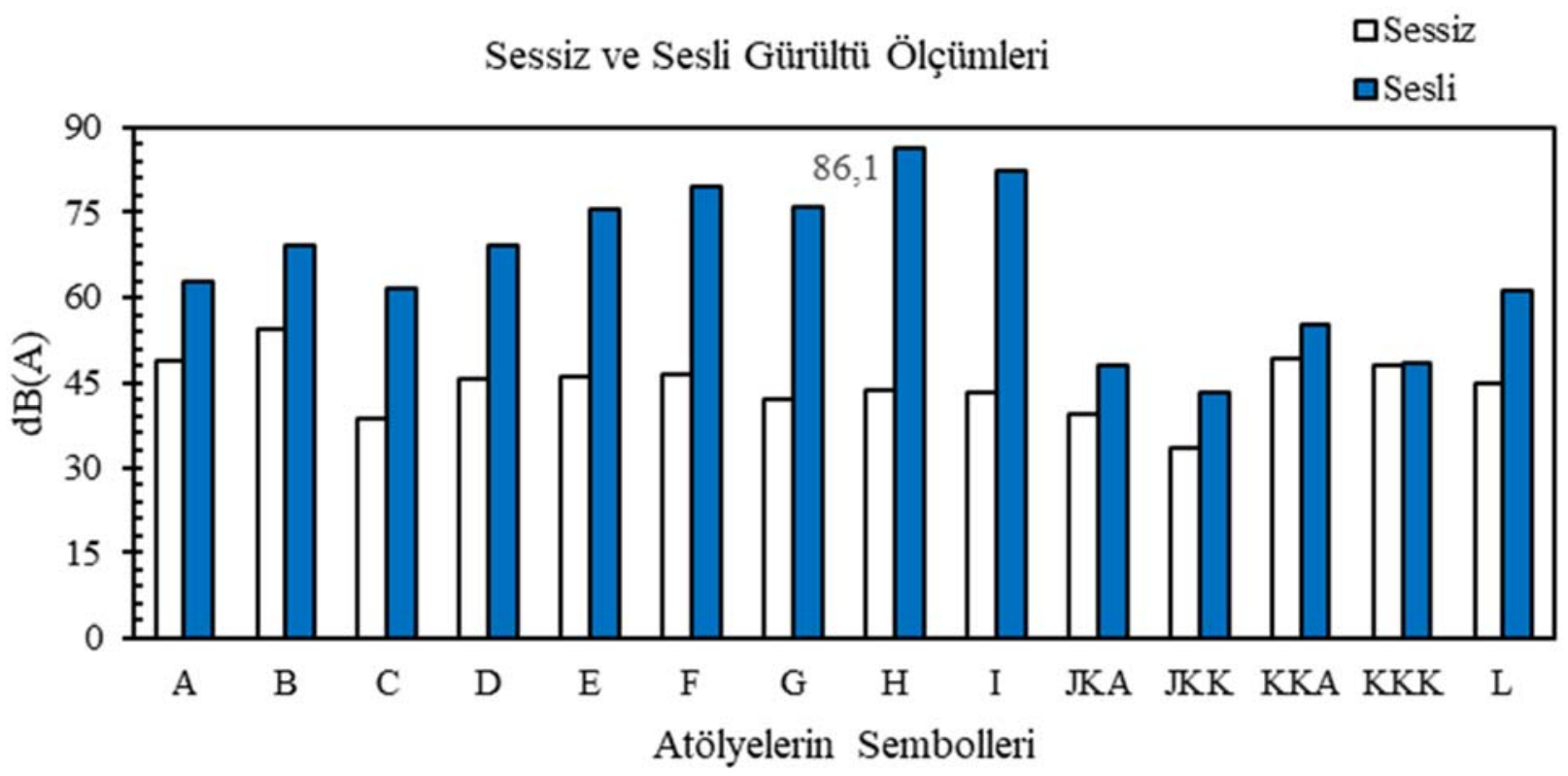

şekilde sac imalatında oluşan gürültünün saç işleme bölümüne geçişini ciddi bir engel oluşması nedeniyle zorlaştırmaktadır. Talaşlı imalat bölümünde sesli ölçülen gürültü değeri $79.3 \mathrm{~dB}(\mathrm{~A})$ olmuştur. Bu ölçüm değeri torna tezgahı çalışırken, talaş kaldırıldığı anda alınmıştır.

Fabrikada çalışma anında idari kısımda ofis de kapı kapalı iken yapılan sesli ölçümde en küçük değer $43.3 \mathrm{~dB}$ (A) ile ölçülmüştür. İdari binada sesli ölçülen en büyük değer ise $61.4 \mathrm{~dB}(\mathrm{~A})$ değeri ile malzeme deposundan alınmıştır.

Ofisten alınan en küçük değer, ofisin yapıdaki konumu nedeniyle olduğu söylenebilir. Ofisin sadece kapısı olup diğer tüm tarafları duvardan ibaret bir mekândır. Bu durum kapı kapatıldığında gürültü açısından korunaklı bir alan oluşumuna sebep olmaktadır. Şekil 2'den de görüldüğü gibi malzeme deposuna çıkış atölyelerin olduğu kısımdandır ve merdiven kullanılmaktadır. Atölyelerin gürültüsü, arada herhangi bir engeli olmayan merdiven boşluğu nedeniyle ve devamında depo girişi kapısı daima açı olduğundan rahatıkla malzeme deposuna taşınabilmektedir.
Bahsedilen yerin etrafı üst katta mekân dışında bulunan iki terasa açılmaktadır ve genelde kapılar açık durumdadır. Çevre gürültüsü teras bölgesinden malzeme deposuna buradan da taşınmaktadır.

Sac imalat, kaynak, montaj bölümleri aralarında herhangi bir bariyer olmayan dışa kapalı, diğer G, F, D, C, B bölümlerine geçişleriyle oluşan bir mekândır. Diğer olarak tanımlanan bölümlerden sac işleme bölümü planda $\mathrm{H}$ kaynak bölümüne karşılık gelmektedir. Kaynak bölümünde gaz altı, elektrik direnç, plazma kesici çalışıyor iken aynı anda sac işleme bölümü, sac imalatı bölümü, montaj bölümü de faaliyette olduğunda kaynak bölümü bunlara göre merkezi bir konumda olması burada ölçülen yüksek değerli gürültünün sebebi olarak söylenebilir.

Sac işleme ve talaşlı imalat bölümlerinde aynı anda birden fazla tezgâhın çalışıyor olma hali nadiren olduğundan bu ölçümlerde de rutin içerisinde değerler alınmıştır. Aynı anda birçok tezgâh çalışıyor iken ölçülen değerlerin üzerinde gürültü değerlerine rahatlıkla çıkılabilmektedir. Mevcut değerler mevcut birimdeki her bir tezgâhın ayrı 
ayrı çalıştığı halde alınan ölçümlerin ortalaması olarak düşünülmelidir. Şekil 2'de A ile tanımlanan süt sağım bölümünde yer alan torna çalışıyor ve montaj yapılıyor iken alınan ölçüm değeridir.

Şekil 2'de D ile tanımlanan boyahanede, rutinde birkaç günde bir periyodik olarak iş yapıldığı ve bu anda gürültüye sebep olan kaynak hava tabancasından çıkan ses olarak belirginleşmektedir.

\section{IV. İŞYERİ ÇALIŞANLARIYLA ANKET ÇALIŞMASI}

İş yerinde, her bir bölümde çalışanlara bazı sorular yöneltilmiştir. Bunlar iş yerindeki bulunma süreleri, yaşları, eğitimleri, iş yerindeki pozisyonları ve işitmeleriyle ilgili olan durumların sorgulanması şeklindedir (Tablo.3).

Eğitim durumlarına göre çalışanlar ilk, orta ve lise seviyelerinde oran olarak dengeli dağılmıştır. Hizmet içi eğitim verildiği takdir de rahatlıkla algılanabilir olduğu görülmektedir. Yönetici kadrosu ise lisans eğitimi seviyesindedir. Çalışanlar genelde (bir kişi hariç) benzer pozisyonlarda devam etmektedirler. Bu iş durumuna göre oluşan gürültünün sürekli aynı şekilde kişiye maruziyeti anlamına gelmektedir. İş yerinde ilginç olan uzun yıllardır çalışılmasına rağmen çalışanlarda, gürültüden dolayı hissedilen işitme kaybı ve işitme kaybına neden olabilecek rahatsızlıklar görülmemesidir. Çalışanların işitme kaybı olmadığı yönündeki beyanlarına rağmen, iş yeri tarafından organize edilen bir işitme kaybı sağlık taraması (odyometri) yapılması sağlanarak gerçek durum anlaşılabilir.

Gürültünün insan sağlığı üzerine etkilerinde, gürültü şiddeti ve süresine göre işitme yitiği yüzdeleri 8 saat/gün etkilenme süresine göre 10 yılda $85 \mathrm{~dB}(\mathrm{~A})$ maruziyette 25 $\mathrm{dB}(\mathrm{A})$ 'lık işitme yitiği \%3 olarak açıklanmıştı, etkilenme süresinin uzun olması halinde işitme yitiği \% değerinin

Tablo 3: İş yerinde yapılan anket sonuçları

\begin{tabular}{|c|c|c|c|c|c|c|c|c|c|c|}
\hline Çalışanlar & 1 & 2 & 3 & 4 & 5 & 6 & 7 & 8 & 9 & 10 \\
\hline $\begin{array}{c}\text { Cinsiyet } \\
\text { E / K }\end{array}$ & $E$ & $E$ & $E$ & $E$ & $E$ & $E$ & $E$ & $E$ & $E$ & $E$ \\
\hline Yaş & 59 & 32 & 53 & 23 & 55 & 37 & 35 & 43 & 23 & 37 \\
\hline $\begin{array}{c}\text { Eğitimi } \\
\text { illk/Orta/Lise/ } \\
\text { Lisans }\end{array}$ & Lisans & Lisans & Orta & Lise & illk & illk & İlk & Orta & Lise & Lise \\
\hline $\begin{array}{l}\text { Fabrikada } \\
\text { Çalışma Yılı }\end{array}$ & 45 & 5 & 38 & 7 & 30 & 14 & $\begin{array}{c}10 \\
\text { Gün }\end{array}$ & 25 & $\begin{array}{c}1 \\
\text { Ay }\end{array}$ & 3 \\
\hline $\begin{array}{c}\text { Mevcut } \\
\text { Pozisyonda } \\
\text { Çalışma Yılı }\end{array}$ & 45 & 5 & 38 & 7 & 30 & 14 & $\begin{array}{c}10 \\
\text { Gün }\end{array}$ & $\begin{array}{l}\text { İhtiyaç } \\
\text { Olan Yer }\end{array}$ & $\begin{array}{c}1 \\
\text { Ay }\end{array}$ & 3 \\
\hline $\begin{array}{c}\text { Farklı } \\
\text { Pozisyonda } \\
\text { Çalışma Yılı }\end{array}$ & 45 & 3 & $x$ & $x$ & $x$ & $x$ & $x$ & 25 & $x$ & $\begin{array}{l}1 \\
1 \\
1\end{array}$ \\
\hline $\begin{array}{c}\text { İşe Girişten } \\
\text { Bugüne İşitme } \\
\text { Kaybı }\end{array}$ & $\begin{array}{c}\text { Var } \\
\text { İlaç Kay- } \\
\text { naklı }\end{array}$ & Yok & Yok & Yok & Yok & Yok & Yok & Yok & Yok & Yok \\
\hline $\begin{array}{c}\text { Rahatsızlık } \\
\text { Kaynaklı İşitme } \\
\text { Kaybı }\end{array}$ & Yok & Yok & Yok & Yok & Yok & Yok & Yok & Yok & Yok & Yok \\
\hline $\begin{array}{c}\text { Sürekli } \\
\text { Kullanılan İlaç }\end{array}$ & Yok & Yok & Yok & Yok & Yok & Yok & Yok & Yok & Yok & Yok \\
\hline
\end{tabular}


daha yükseldiği bilinmektedir [17]. Mevcut iş yerinde 5 kişinin 10 yıl üzerinde çalışma süresi dikkate alındığında, işitme kaybı ile ilgili bir değerlendirmenin yapılması gereği açıktır.

\section{SONUÇLAR}

Çalışmada tarım makinaları üretimi yapan bir firmada, malzemelerin ürün haline gelişine kadar olan süreçte, fabrikadaki birimlerde olan alet ve cihazlar ile bunların oluşturdukları gürültü değerleri belirlenmiş ve görevli çalışanlar üzerine bunun etkileri incelenmiştir.

Fabrikada rutin çalışan makinalar nedeniyle kararlı bir gürültüden bahsedilebilir. Ölçüm anında gürültü düzeyi dağılımı, çalışma şekline bağlı olarak dalgalı, kesikli, darbe şekillerinde olabilmektedir [16]. Dolayısıyla çalışma anında işin planına göre yukarıdaki gürültü tipleri devreye girerek tek veya birçoğu birlikte devrede olduğu halde gürültü değerleri vermektedir.

Fabrikada ölçülen gürültü seviyelerine göre (Tablo 1), sac imalatı ve montaj bölümü arasında yer alan kaynak bölümünde en yüksek değer $86.1 \mathrm{~dB}(\mathrm{~A})$ olarak elde edilmiştir. Montaj bölümünde de $82.1 \mathrm{~dB}(\mathrm{~A})$ ve talaşlı imalat bölümünde ise $79.3 \mathrm{~dB}(\mathrm{~A})$ dır. Devamında sac işleme 76.1 $\mathrm{dB}(\mathrm{A})$ ve sac imalatı $75.7 \mathrm{~dB}(\mathrm{~A})$ olarak elde edilmiştir. Gürültülü ortamlarda konuşulanların anlaşılamaması en sık yakınmadır. Yüksek frekanslı seslerle konuşan kadın ve çocuklar konuşma seslerini işitseler de anlamaları yetersizdir ve gürültülü çevrede kulak daha hızlı yaşlanır $[17,18]$. Gürültü akustik travma, uyku problemleri, kardiyovasküler sistem üzerinde olumsuzluk, psikolojik rahatsızlık ve performansı olumsuz etkilediği bilinmektedir $[13,19,20,21,22]$.

Çalışma anında yapılan ölçümlerde çalışanlar tarafın- dan olumsuz bir durum belirtilmemiş olmasına rağmen literatürden açık olduğu üzere özellikle de zamana bağlı olarak çalışanlar üzerinde yukarıdaki etkilerin var olabileceği söylenebilir. Gürültü yönetmeliğine göre mevcut iş yeri değerlendirildiğinde maruziyet sınır değerleri en yüksek gürültü değeri 8 saat için $86.1 \mathrm{~dB}(\mathrm{~A})$ ve altında elde edildiğinden, işverenlerin yükümlülükleri ve risklerin belirlenmesi ve değerlendirilmesi kapsamında, maruziyetin önlenmesi ve azaltılması için kişisel korunma işçilerin eğitimi ve katılımının sağlanması, çalışanların işitme ile ilgili sağlık kontrollerinin yapılması ve sürdürülebilirliği gerekmektedir [1].

\section{KAYNAKLAR}

[1] “Çalışanların Gürültü İle İlgili Risklerden Korunmalarına Dair Yönetmelik”; Resmi Gazete; Sayı:28721; 28 Temmuz 2013.

[2] Özgüven M.M.; 2012, "Kapalı Alanlarda Kullanılan Bazı Hasat Sonrası Tarım Makinalarının Gürültü Haritalarının İncelenmesi” Tekirdağ Ziraat Fakültesi Dergisi ; 9(3); 45-53.

[3] Baydur H.; Saatli G.; "Bir Termik Santralde İş Kazalarının Değerlendirilmesi”; II. İş Sağlığ1 ve Güvenliği Kongresi Bildirileri-İSG-01-2003”; 02-03 Mayı2003; Adana, TMMOB, Makine Mühendisleri Odası Yayın No: E/2003/317; Sayfa:17-15.

[4] Sağbaş A.; Kahraman F.; Eşme U.; Özbek A.; 2008, "Tekstil İşletmelerinde Gürültü Ve Gürültünün Azaltılmasında Mühendislik Önlemler” Ç.Ü. Müh. Mim. Fak. Dergisi ; 23(1); 181-187.

[5] Dedeler H.; "Bir İşletmede İşyeri Fiziksel Risk Etmenlerinin Çalışanların Sağlığına Olan Etkisinin Saptanması ve Değerlendirilmesi”; Trakya Üniversitesi, Sağlık Bilimleri Enstitüsü, Halk Sağlığı Anabilim Dalı, Y.L. Tezi; Edirne, 2008.

[6] Ediz G.; Beyhan S.; Akçakoca H.; Sarı E.; "Madencilikte Gürültüye Bağlı İşitme Kayıplarının İncelenmesi”; Türkiye 13. Kömür Kongresi Bildiriler Kitabı, 29-31 Mayıs 2002, Zonguldak, Türkiye.

[7] Ayaz B.; “Takım Tezgahlarında Verim Kaybının Ve Gürültü Faktörünün Araştırılması”; Osmangazi Üniversitesi, Fen Bilimleri Enstitüsü, Makine Mühendisliği Anabilim Dalı, Y.L. Tezi, Ocak, 2006. 
[8] Şengün N.; Altındağ R.; Demirdağ S.; "Dairesel Testerelerle Kesme İşleminde Testere Devir Sayısının Ve Gürültü Seviyesi Değişimlerinin İncelenmesi”; Pamukkale Üniversitesi Mühendislik Bilimleri Dergisi, Cilt 19, Sayı 3, 2013, Sayfalar 121-126.

[9] Serin H.; Şahin Y.; Durgun M.; "Küçük Ölçekli Mobilya İşletmelerinde Gürültü Analizi”; Ormancılık Dergisi; 9(2); (2013); 1-8.

[10] Singh L. P.; Bhardwaj A.; Deepak K. K.; "Occupational exposure in small and medium scale industry with specific reference to heat and noise"; Noise \&Health; Vol.: 12; Issue: 46; Page:37-48; Year: 2010.

[11] Kim B. S.; Park J. Y.; Lee Y. U.; "A noise generating mechanism at manuacturing process of metal material products- focus on small and medium size enterprise."; Journal of Korean Society of Mechanical Technology; 15(6); 925-930; 2013.

[12] Melemez K.; 2015, "Mobilya Üretimi Yapılan İşletmelerde Gürültü, Titreşim ve Odun Tozunun Ergonomik Etkilerinin İncelenmesi” TÜBİTAK Projesi; Proje Kodu 1002/No 114 Y043.

[13] T.C. Çevre ve Şehircilik Bakanlı̆̆ Çevre Yönetimi Genel Müdürlüğü Gürültü ve Titreşim Kontrolü Şube Müdürlüğü, "Gürültünün İnsan Sağllğı Üzerine Etkileri”, http://www.ormansu.gov.tr/404.html? aspxerrorpath=/gurultu/AnaSayfa/gurultu/ sagliketkileri.aspx , Erişim Tarihi:09.03.2018.

[14] "Noise"; United States Department of Labor; Occupational Safety\&Health Administration; Section III; Chapter 5; OSHA Technical Manual; 2016.

[15] Darpe A. K.; "Fundamentals of Noise"; Department of Mechanical Engineering IIT Delhi. Dec. 18; 2015.

[16] Güler Ç. , Çobanoğlu Z. Gürültü. Sağlık Bakanlığı. Çevre Sağlığı Temel Kaynak Serisi No:19. Ankara, 1994.

[17] Badur T. Gaziantep Kent Merkezi'nin Gürültü Haritası ve Gürültünün İşitsel Etkileri Üzerine Bir Çalışma (Uzmanlık Tezi). Gaziantep: GÜ Tıp Fak; 1997.

[18] Su BA. Ergonomi. Pano Ofset. 123-42. Ankara, 2001

[19] Alberti PW. Noise and the ear. In; Kerr AG, Stephens D (Ed.). Scott-Brown's Otolaryngology vol.2, London: Butterworth-Heinemann Read Educational and Professional Publishing Ltd. ch 11,1-34, 1997.

[20] Wallace RB (Ed.). Maxy-Rosenau-Last Public Health \& Pretentive Medicine. Moller RA. Effects of the Physical Environment: Noise As a health hazard; Appleton \& Lange. 14th Edition. stamford. USA.
637-44, 1998.

[21] Türkiye Çevre Sorunları Vakfı (TR). Türkiye'nin Çevre Sorunları.TÇSV; Ankara, 1989.

[22] Porter ND, Berry BF. Noise and nuisance policy hesalth effect based noise assessment methods: A review and feasibility study. Department for Environment, Food and Rular Affairs; Sept. 1998. 